Presented at the Materials Research Society Fall Meeting,

* Boston, Dec. 2-6, 1996.

\title{
ANNEALING STUDIES OF VISIBLE LIGHT EMISSION FROM SILICON NANOCR YSTALS PRODUCED BY IMPLANTATION
}

G. Ghislotti (a) , B. Nielsen ${ }^{(a)}$, L. F. Di Mauro ${ }^{(b)}$, B. Sheey ${ }^{(b)}$, P. Mutti ${ }^{(c)}$, A. Pifferi ${ }^{(c)}$, P. Taroni $^{(c)}$, L. Valentini ${ }^{(c)}$, F. Comi ${ }^{(d)}$, R. Tonini ${ }^{(d)}$

(a)Department of Applied Science, Brookhaven National Laboratory, Upton, N.Y. 11973

(b)Department of Chemistry, Brookhaven National Laboratory, Upton, N.Y. 11973

(c)Dipartimento di Fisica, Politecnico di Milano, 20133 Milano Italy

(d)Dipartimento di Fisica, Universita di Modena, Modena, Italy

\section{ABSTRACT}

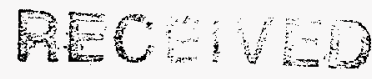

MAP 25 得

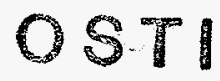

The annealing behavior of silicon implanted $\mathrm{SiO}_{2}$ layers is studied using continuous and timegated photoluminescence (PL). Two PL emission bands are observed. A band centered at $560 \mathrm{~nm}$ is present in as implanted samples and it is still observed after $1000^{\circ} \mathrm{C}$ annealing. The emission time is fast $(0.2-2 \mathrm{~ns})$. A second band centered at $780 \mathrm{~nm}$ further increases when hydrogen annealing was performed. The emission time is long ( $1 \mu \mathrm{s}-0.3 \mathrm{~ms}$ ).

\section{INTRODUCTION}

Ion implantation is a promising technique for producing silicon nanocrystals ( $\mathrm{Si}_{\mathrm{nc}}$ ) in a dielectric matrix. The basic idea in this approach is to enrich by ion implantation the silicon concentration in a dielectric matrix. Subsequent thermal annealing can promote the formation of crystalline precipitates having nanometric dimensions. Ion implantation which is a well established technique in microelectronics, presents some extra advantages: the control of the depth and width of the region of $\mathrm{Si}_{\mathrm{nc}}$ formation, and the possibility to implant different ions in different substrates.

Photoluminescence (PL) from $\mathrm{Si}_{\mathrm{nc}}$ produced by ion implanation has been reported by several authors [1-4]. Shimizu-Iwayama et al. [2] presented data of room temperature luminescence from $1 \mathrm{Mev} \mathrm{Si}{ }^{+}$implanted fused silica. Komoda et al. [3] observed a band centered at $600 \mathrm{~nm}$, and a red shift that was interpreted as due to an increase in the size of $\mathrm{Sinc}_{\mathrm{nc}}$. The observation of near infrared and blue-green light emission in $\mathrm{SiO}_{2}$ layers implanted at $1 \times 10^{17} \mathrm{~cm}^{-}$ 2 and annealed at high temperature $\left(T>1000^{\circ} \mathrm{C}\right)$ has been reported by some of us [4- 6].

In spite of the many investigations, a complete study of the kinetics of formation of the two emission bands as a function of different preparation conditions, and of their emission times has not been performed. This study could provide a better understanding of the physical parameters which influence the luminescence mechanism. At the same time, this can also be of pratical interest to improve the PL intensity in view of possible optoelectronics applications. To address some of these issues, in this paper continuous and time-gated PL studies of $\mathrm{Si}^{+}$implanted $\mathrm{SiO}_{2}$ layers were performed starting from as-implanted samples.

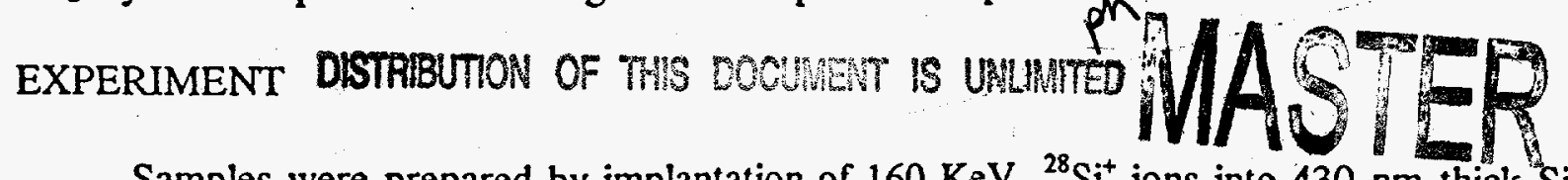

Samples were prepared by implantation of $160 \mathrm{KeV}{ }^{28} \mathrm{Si}^{+}$ions into $430 \mathrm{~nm}$ thick $\mathrm{SiO}_{2}$ layers thermally grown on a (100) oriented p-type Si substrate. Fluences ranged from $3 \times 10^{16}$ 
$\mathrm{cm}^{-2}$ to $3 \times 10^{17} \mathrm{~cm}^{-2}$. Vacuum annealing was performed in a high-vacuum chamber (10 ${ }^{-7}$ torr) and the sample was mounted on a resistively heated tantalum foil. Gas anncaling was done in a furnace using high purity gases. In the casc of hydrogen annealing a $15 \% \mathrm{H}_{2}, 85 \% \mathrm{Ar}$ mixture was used.

Photoluminescence measurements were performed using $464 \mathrm{~nm}$ excitation light from an excimer pumped dye laser. Emitted light was detected using an intensified charge coupled device (ICCD) detector. Nanosecond time-resolved spectroscopy was performed using a mode-locked krypton ion laser oscillating at $413 \mathrm{~nm}$ (sec [7] for details on the experimental apparatus).

\section{RESULTS AND DISCUSSION}

Figure 1 represents photoluminescence (PL) spectra for samples implanted at different doses $\left(3 \times 10^{16}-3 \times 10^{17} \mathrm{~cm}^{-2}\right)$ and annealed for $30 \mathrm{~min}$. at $1000^{\circ} \mathrm{C}$. Two bands are observed: a green-blue band peaked at $560 \mathrm{~nm}$, and a near-infrared one centered at $780 \mathrm{~nm}$. This latter is observed only for an implantation dose higher than $1 \times 10^{17} \mathrm{~cm}^{-2}$, which corresponds to a Si excess in the implanted region higher than $5 \%$ at.. PL intensity at $560 \mathrm{~nm}$ and $780 \mathrm{~nm}$ for sample implanted at $2 \times 10^{17} \mathrm{~cm}^{-2}$ after annealing at different temperatures for $30 \mathrm{~min}$. is reported in fig. 2a. The intensity of the 560 $\mathrm{nm}$ band increases as a function of the annealing temperature up to $1000^{\circ} \mathrm{C}$. A band centered around $780 \mathrm{~nm}$ is detected only after annealing at $1000{ }^{\circ} \mathrm{C}$ was performed. The near-infrared band grows for increasing annealing time (see Fig. 2b).

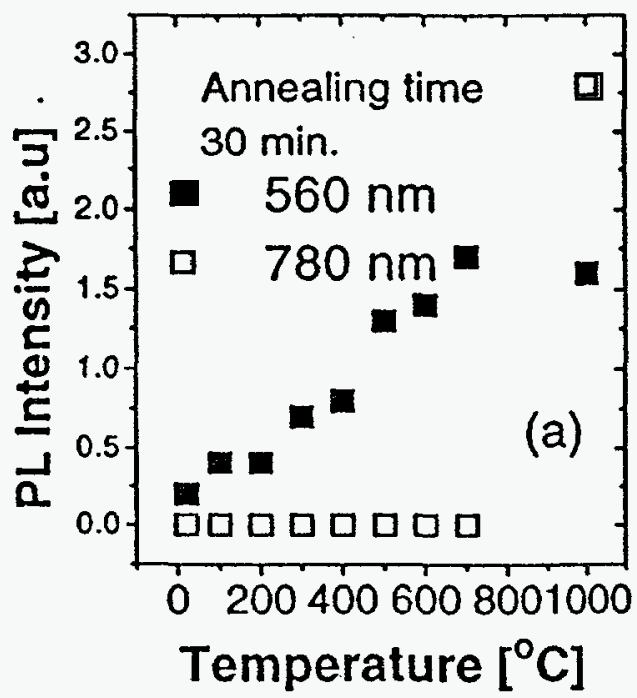

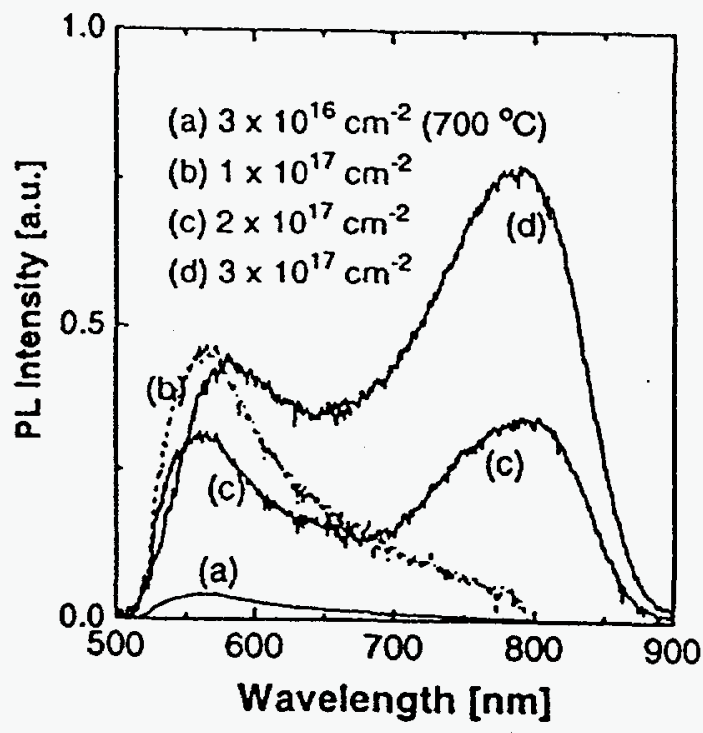

Fig.1. PL intensity for samples implanted at dilferent doses and annealed $\mathbf{3 0} \mathrm{min}$. at $1000^{\circ} \mathrm{C}$.

Fig. 2. Effect on PL intensity of annealing temperature (a), and time (b) for sample implanted at $2 \times 10^{17} \mathrm{~cm}^{-2}$. 
To study the effect of hydrogen, a sample prepared by implanting at $2 \times 10^{17} \mathrm{~cm}^{-2}$ fluence and annealed $30 \mathrm{~min}$. at $1000{ }^{\circ} \mathrm{C}$, was subsequently annealed in $\mathrm{H}_{2}$ atmosphere at $500{ }^{\circ} \mathrm{C}$. The intensity in the near-infrared spectral region increases after hydrogen annealing and saturates after about 3 hours annealing, whereas the PL intensity for the blue-green light remains almost the same (see Fig 3). The temporal evolution of the PL signal was studied using time-gated spectroscopy. In the case of sample implanted at $1 \times 10^{17} \mathrm{~cm}^{-2}$ and annealed $30 \mathrm{~min}$. in argon at $1000^{\circ} \mathrm{C}$, for very short time gates $(0-0.5 \mathrm{~ns}$, 2-5 ns) after the excitation pulse PL emission is peaked around $510 \mathrm{~nm}$ (see Fig. 4a ). For the sample corresponding to an implantation dose of $2 \times 10^{17} \mathrm{~cm}^{-2}$ and annealed under the same conditions, the fast component is shifted at a longer wavelength, while a longer component appears (Fig. 4b).

Gated PL spectra for this sample on a longer time-scale are shown in Fig.5. For gates of 1 $\mu \mathrm{s}-10 \mu \mathrm{s}$ the emission is centered at $750 \mathrm{~nm}$. When the time gate is increased the PL emission is centered at a longer wavelength ( $800 \mathrm{~nm}$ when the gate is in the range $10 \mu \mathrm{s}-0.3 \mathrm{~ms}$ ).

The observation of a green emission band in $\mathrm{Si}$ implanted $\mathrm{SiO}_{2}$ layers has been reported by several authors [3,4-6]. Present data show that it is present in as implanted samples, it increases as a function of the annealing $\mathrm{T}$ up to $1000{ }^{\circ} \mathrm{C}$, and the emission time is very fast. An emission around $600 \mathrm{~nm}$ and related to defects (twofold coordinated $\mathrm{Si}$ atoms bonded to two oxygen atoms) is observed in $\mathrm{SiO}_{2}[8,9]$. However these defects are characterized by radiative times of the order of $\mu$ s [9].

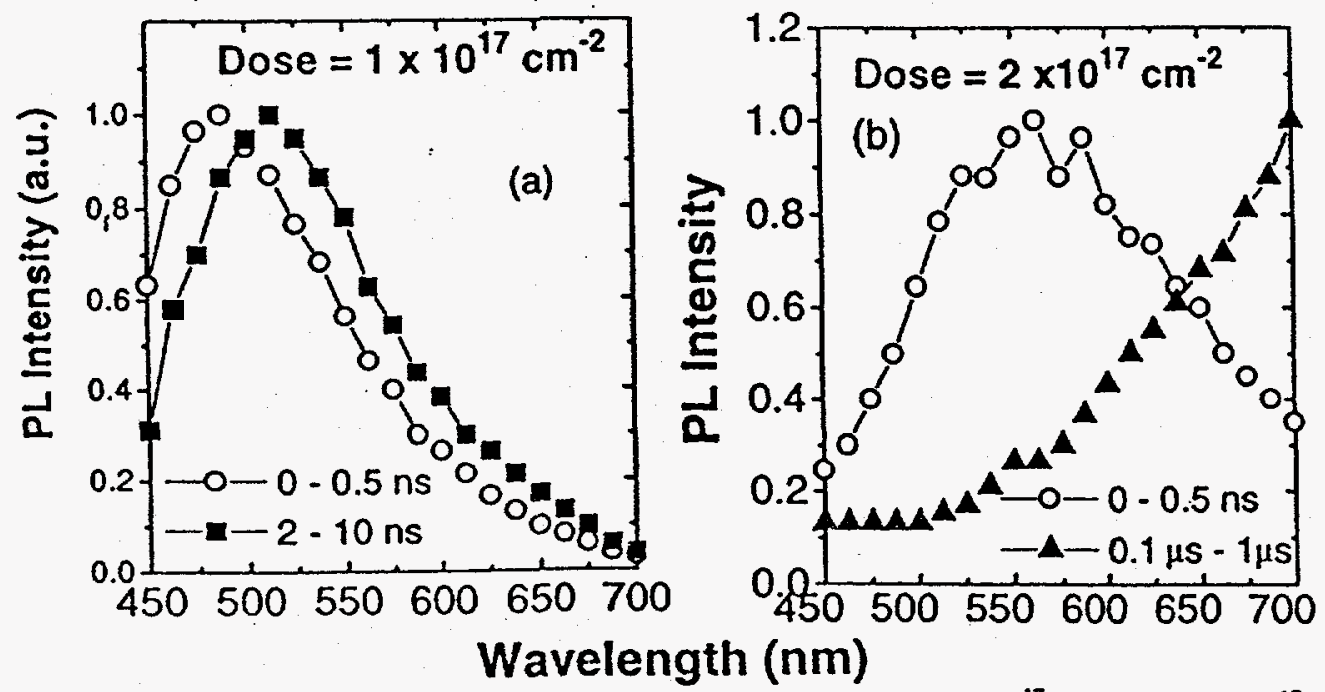

Fig.4 Nanosecond time-resolved gated spectra for samples implanted at $1 \times 10^{17}(\mathrm{a})$, and $2 \times 10^{17} \mathrm{~cm}^{-2}$ and annealed at $1000^{\circ} \mathrm{C}$. 


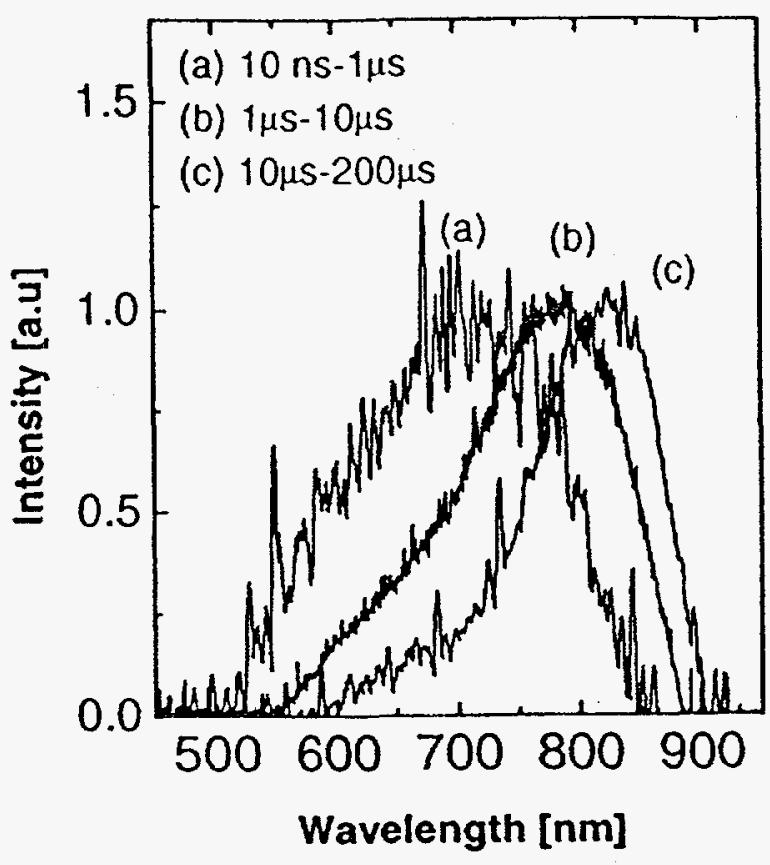

Fig.5 Gated spectra for sample corresponding to $2 \times 10^{17} \mathrm{~cm}^{-2}$ dose for different time gates.

Previous annealing studies conducted on samples under investigation have shown that these defects anneal out above $700{ }^{\circ} \mathrm{C}$ [10]. The annealing behavior and the fast decay time seem to exclude that this band originates from the point defects mentioned above.

Fast lifetimes for silicon-based nanostructures are reported to be related with chain or ladderlike structures. Kanemitsu et al. [11] reported that linear or ladder structures of Si atoms can give a luminescence signal in the spectral region around $500 \mathrm{~nm}$ and they have radiative times of the order of ns, while cubic silicon clusters have radiative times of the order of $\mathrm{ms}$ [12]. Moreover Si clusters are more influenced by the presence of non-radiative centers at their surface [12, 13]. The behavior observed for the green light emission presents some similarities with results recently obtained by Augustine et al. [14] on amorphous silicon oxynitrides produced by plasma-enhanced chemical vapor deposition. They reported a fast (less than $10 \mathrm{~ns}$ ) green emission which does not depend on annealing atmosphere. and which shows analogies with organosilane chemical compounds [15].

Present results could be therefore consistently explained assuming that after implantation in the Si-rich region corresponding to the end of range Si extended defects having such a molecular-like stucture (chain or ladder) are formed. These structures can act as radiative sites. Since the radiative times for the emission at $560 \mathrm{~nm}$ are fast, the luminescence intensity is not influenced by non-radiative processes which are usually characterized by capture rates of the order of ms [16]. This may explain why the intensity is not affected by hydrogen annealing. While based on annealing behavior both small silicon clusters and Si-chain or ladder structures can be responsible for the $560 \mathrm{~nm}$ band, the fast lifetime and the insensitivity to annealing atmosphere (argon, nitrogen, hydrogen) seem to indicate that the latter are the most probable candidates.

Near infrared light is observed only after anncaling at high temperature and for implantation doses higher than $1 \times 10^{17} \mathrm{~cm}^{-2}$. After implantation a Si-rich $\mathrm{SiO}_{2}\left(\mathrm{SiO}_{\mathrm{x}}, \mathrm{x}<2\right)$ is produced, Si excess depending on the dose. If annealing temperature is raised to (or above) 1000 ${ }^{\circ} \mathrm{C} \mathrm{SiO}$ becomes unstable $[17,18]$ and $\mathrm{Si}$ precipitates are known to be formed [19-21]. This is supported also by several TEM showing the presence of $\mathrm{Si}$ nanocrystals inside the $\mathrm{SiO}_{2}$ matrix $[3,4$,$] . Therefore the observation of a red band is related with the formation of Si precipitates$ (although not necessarily related to a recombination within the $\mathrm{Si}_{\mathrm{cc}}$ ). The observed annealing time behavior (see Fig. 2b), is consistent with a Ostwald ripening process (disappearence of smaller precipitates and formation of bigger ones).

Finally the observed emission times for the near-infrared light (from $1 \mu \mathrm{s}$ to $0.3 \mathrm{~ms}$ ) are on a timescale comparable with that of non-radiative recombination processes. Centers like $\mathrm{Si}$ dangling bonds can represent important non-radiative channels. Lannoo et al. [13] showed that 
even few $\mathrm{Si}$ dangling bonds can completely quench the PL emission from a $\mathrm{Si}_{\mathrm{nc}}$. Since hydrogen is known to passivate the $\mathrm{Si}-\mathrm{SiO}_{2}$ interface $[22,23]$, the improvement in PL intensity, after hydrogen annealing (fig.3), can be explained assuming that passivation of Si dangling bonds at the $\mathrm{Si}_{\mathrm{nc}}-\mathrm{SiO}_{2}$ interface is taking place.

\section{CONCLUSIONS}

Two emission bands are detected in $\mathrm{SiO}_{2}$ layers implanted with $\mathrm{Si}^{+}$ions al doses of $3 \times 10^{16} \mathrm{~cm}^{-2}$ $3 \times 10^{17} \mathrm{~cm}^{-2}$. The first centered at $560 \mathrm{~nm}$ is present in as-implanted samples, increases its intensity as a function of the annealing temperature, and it is characterized by fast emission (0.2-2 $\mathrm{ns)}$. A second band around $750 \mathrm{~nm}$ is detected after $1000^{\circ} \mathrm{C}$ annealing was performed. The fast emission time and the annealing behavior suggest that the green emission is related to extended defects, while the near-infrared light is related to the presence of silicon precipitates.

\section{REFERENCES}

[1] H. A. Atwater, K. V. Shcheglov, S. S. Wong, K. J. Vahala, R. C. Flagan, M. L. Brongersma, A. Polman, Mat. Res. Soc. Symp. Proc. 316, 409 (1994)

[2] T. Shimizu-Iwayama, K. Fujita, S. Nakao, K. Saitoh, T. Fujita, and N. Itoh, J. Appl. Phys. 75, 7779 (1994)

[3] T. Komoda, J. Kelly, F. Cristiano, A. Nejim, P.L.F. Hemment, K.P. Homewood, R. Gwilliam, J.E. Mynard, and B.J. Sealy, Nucl Instr. and Methods B 96, 387 (1995)

[4] P. Mutti, G. Ghislotti, S. Bertoni, L. Bonoldi, G.F. Cerofolini, L. Meda, E. Grilli, and M. Guzzi, Appl. Phys. Lett. 66, 851 (1995)

[5] P. Mutti, G. Ghislotti, L. Meda, E. Grilli, M. Guzzi, L. Zanghieri, R. Cubeddu, A. Pifferi, P. Taroni, and A. Torricelli, Thin Solid Films 276, 88 (1996)

[6] G. Ghislotti, B. Nielsen, P. Asoka-Kumar, K. G. Lynn, A. Gambhir, L. F. DiMauro, C. E. Bottani, J. Appl. Phys. 79, 8660 (1996)

[7] R. Cubeddu, F. Docchio, W. Q. Liu, R. Ramponi, and P. Taroni, Rev. Sci. Instrum. 59, 2254 (1988)

[8] L. Skuja, J. Non-Cryst. Solids 14977 (1992)

[9] L. Skujia, Solid State Commun. 84613 (1992)

[10] G.Ghislotti, B. Nielsen, P. Asoka-Kumar, K.G. Lynn, C. Szeles, C.E.Bottani, S.Bertoni, G.F.Cerofolini, and L. Meda, Thin Solid Films 276 (1996)

[11] Y. Kanemitsu, K. Suzuki, S. Kyushin, H. Matsumoto, Phys. Rev B 51, 13103 (1995)

[12] Y. Kanemitsu, K. Suzuki, M. Kondo, S. Kyushin, H. Matsumoto, Phys. Rev. B 51, 10666 (1995)

[13] M. Lannoo, C. Delerue, and G. Allan, J. of Lumin. 57, 249 (1993)

[14] B.H. Augustine, E.A. Irene, Y.J. He, K.J. Price, L.E. McNeil, K.N. Christensen, and D.M. Maher, J. Appl. Phys. 78, 4020 (1995)

[15]S. Kyushin, H. Matsumoto, Y. Kanemitsu, and M. Goto, J. Phys. Soc. Jpn. 63, 46 (1988)

[16] D. Goguenheim and M. Lannoo, Phys. Rev. B 44, 1724 (1991)

[17] D. Dong, E.A. Irene, and D.R Young, J.Electrochem. Soc. 125, 819 (1978)

[18] F. Rochet, G. Dufar, H. Roulet, B. Pelloie, J. Perrière, E. Fogarassy, A. Slaoui, and M. Froment, Phys. Rev. B 37, 6468 (1988)

[19] L.A. Nesbit, Appl. Phys. Lett. 46, 38 (1985)

[20] C. Jaussand, J. Margail, J. Stoemenos, and M. Bruel, MRS Symp. Proc., 107, 17 (1988) 
[21] S. Mantl, Mater. Sci. Rep. 8, 1 (1992)

[22] K.L. Brower, Phys. Rev. B 42, 3444 (1990)

[23] M.L Reed, Semicond. Sci. Technol. 4, 980 (1989)

\section{ACKNOWLEDGMENT}

This research was performed under the auspices of the U.S. Department of Energy, Division of Materials Sciences, Office of Basic Energy Sciences under Contract No. DE-AC02$76 \mathrm{CH} 00016$. 


\section{DISCLAIMER}

This report was prepared as an account of work sponsored by an agency of the United States Government. Neither the United States Government nor any agency thereof, nor any of their employees, make any warranty, express or implied, or assumes any legal liability or responsibility for the accuracy, completeness, or usefulness of any information, apparatus, product, or process disclosed, or represents that its use would not infringe privately owned rights. Reference herein to any specific commercial product, process, or service by trade name, trademark, manufacturer, or otherwise does not necessarily constitute or imply its endorsement, recommendation, or favoring by the United States Government or any agency thereof. The views and opinions of authors expressed herein do not necessarily state or reflect those of the United States Government or any agency thereof. 


\section{DISCLAMMER}

Portions of this document may be illegible in electronic image products. Images are produced from the best available original document. 